Article type : Original Manuscript

\title{
Characterization of melanoidins derived from Brewers' spent grain: New insights into their structure and antioxidant activity
}

Running title: Structural characterization of melanoidins

$$
\text { Mariela Patrignani }{ }^{1} \text {, Lucía del Sol González-Forte }{ }^{1,2}
$$

1 Centro de Investigación y Desarrollo en Criotecnología de Alimentos (CIDCA), Facultad de Ciencias Exactas, UNLP-CIC- CCT La Plata -CONICET, 47 y 116, 1900 La Plata, Argentina

2 Facultad de Ciencias Agrarias y Forestales, UNLP, 60 y 116, 1900 La Plata, Argentina

\section{Correspondent:}

Fax: +54 221425 4853;

E-mail: marielapatrignani@biol.unlp.edu.ar; mariela_patrignani@hotmail.com

\section{Abstract}

Melanoidins, formed at the final stages of Maillard reaction (MR) present important physiological activities, but their structure and reaction pathways are largely unknown in real food systems. In the present work, these bioactive compounds derived from Brewers' spent grain (BSG) with different roasting degrees were analyzed.

This article has been accepted for publication and undergone full peer review but has not been through the copyediting, typesetting, pagination and proofreading process, which may lead to differences between this version and the Version of Record. Please cite this article as doi: $\underline{10.1111 / \text { ijfs. } 14653}$

This article is protected by copyright. All rights reserved 
Results showed that BSG could be considered a more important source of bioavailable antioxidants than what it was reported in previous studies. During MR development, proteinic structures are partially lost while a carbohydrate skeleton is formed. The crystallinity is reduced and the structure sets into a conformation with a peak centred at $20^{\circ}(2 \theta)$, stable with the increasing thermal treatment. While MR continues the development of browning compounds increases, the antioxidant activity rises and phenolic compounds are bind to the melanoidin structure $(P \leq 0.05)$. Moreover, FTIR analysis showed a dominance of a-glyosidic linkage and the presence of furanose rings in the melanoidins structure.

\section{Keywords}

Brewery waste- Brewers' spent grain- Melanoidins- Structure analysis- Antioxidant activity

\section{Introduction}

Brewers' spent grain (BSG) is the major by-product of the brewing industry. The average annual global production of BSG is estimated to be 39 million tonnes and it mostly is used as a low-value animal feed. Nonetheless, BSG is an important source of bioactive compounds. It contains a high amount of antioxidant phenolic compounds such as hydroxycinnamic acids ferulic, and p-coumaric acids (Lynch et al., 2013). Moreover, recent research has indicated that, as a result of barley grain roasting, BSG also contains important amounts of Maillard reaction products (MRP) (Connolly et al., 2013; Piggott et al., 2014).

The Maillard reaction (MR) is a type of non-enzymatic browning central to food chemistry because it leads to changes in flavour, taste and texture during processing (Bruhns et al., 2019). Besides, in recent years, intertest has been focused on the biological activities of high molecular weight (HMW) products (better known as melanoidins) formed at the final stages of the MR. Melanoidins, exhibit an important antioxidant, antihypertensive and prebiotic activity that has been described in real food 
systems (Wang et al., 2011). Thus, the interest in melanoidins has increased dramatically in the last decade.

Melanoidins are coloured, nitrogen-containing polymeric compounds. However, their structure and reaction pathways are largely unknown, mainly because the complex array of melanoidins is strongly dependent on the type of food, the technological conditions of the reaction, $\mathrm{pH}$ and the composition of the reagents involved (Wang et al., 2011). A current study performed by Mohsin et al. (2020) has tackled the different chemical pathways for melanoidins formed from glucose, alanine and fructosylalanine. While Bruhns et al. (2019) evaluated the formation mechanism involved in the MR of Dglucose and $\mathrm{y}$-aminobutyric acid at low water content. However, these analyses were performed using over-simplistic model systems, and little work has been done on real food systems.

A recent research performed by Yang et al. (2019) evaluated the content and preliminary structure of melanoidins isolated from the spent grains of a Chinese liquor. Nonetheless, it would be of major significance perform these analyses on BSG, as beer is the fifth most consumed beverage in the world (Olajire, 2020). On the other hand, although previous studies performed by Piggott et al. (2014) and Carvalho et al. (2014) analyzed MRP on beer by products and barley, these analyses only considered the chemical aspects of these bioactive compounds and currently there is not a proper description of the structure and the physical characteristics of HMW MRP derived from BSG.

Considering the importance of melanoidins in the diet and their physiological effects, an accurate assessment of their structure is of striking significance. In the present work the physical characteristics of these MRP as well as their relationship with their molecular structure were detailed studied. Moreover, the present work provides new insights into the antioxidant activity of these macromolecules. This is the first approach to understand the molecular stabilization process involved in the development of MRP derived from BSG. Besides, it could be the starting point for further applications of MRP as potential functional ingredients and for the development of tailor-made melanoidins.

\section{Materials and Methods}




\section{Materials}

BSGs with different roasting levels (Pilsen, Caramel 60, Caramel 120 and Chocolate) were obtained in the laboratory under equivalent industrial conditions (Palmer, 2006). Sodium carbonate, sodium acetate and acetic acid were supplied by Biopack. DPPH reagent, gallic acid, Folin-Ciocalteu reagent, 6-Hydroxy-2,5,7,8-tetramethylchromane-2carboxylic acid (Trolox standard), ABTS reagent and potassium persulphate were purchased from Sigma-Aldrich, while TPTZ reagent was supplied by Fluka Chemicals. All these chemicals were of analytical grade.

\section{In vitro digestion and antioxidant determination}

The digestion process of BSG samples was performed according to Patrignani et al. (2019). The antioxidant capacity of the soluble fraction and the solid residue obtained was determined by three different methods: DPPH, ABTS and FRAP. All the determinations were performed at least in duplicate, and the results were expressed as $\mu \mathrm{mol}$ Trolox equivalents per $\mathrm{mg}$ of dried sample. The global antioxidant capacity of the samples was calculated as the sum of the antioxidant capacity of the two fractions obtained. A detailed description of the techniques used can be found in the Supporting Information of this manuscript.

\section{Aqueous extraction of melanoidins from BSG and characterization}

The extraction of melanoidins from BSG was performed in accordance with Piggott et al. (2014). A proper amount of BSG was subjected to aqueous extraction $(1: 15 \mathrm{dw} / \mathrm{v})$ at 70 ${ }^{\circ} \mathrm{C}$ for $1 \mathrm{~h}$. Then, samples were centrifuged $4190 \mathrm{~g}$ for $20 \mathrm{~min}$, and dialysed for $4 \mathrm{~h}$ against water at $60{ }^{\circ} \mathrm{C}$ with constant stirring (four water changes). The HMW retentate $(>12 \mathrm{KDa})$ was freeze-dried weighed and stored at $-20^{\circ} \mathrm{C}$.

The isolated MRP were resuspended in an appropriate volume of distilled water $(0.6 \mathrm{mg} / \mathrm{mL})$ and the UV-Vis spectrum $(400-700 \mathrm{~nm})$ was determined in duplicate for each sample. Also, sugar and protein concentration was measured by the anthrone and Bradford methods respectively (Piermaria et al., 2015). 


\section{Determination of antioxidant activity and total phenolic content in melanoidins}

The total phenolic content (TPC) of melanoidins was determined at least in triplicate on the solution obtained after aqueous hydrolysis and extraction (see previous section). Briefly, $25 \mu \mathrm{L}$ of the extract and $50 \mu \mathrm{L}$ of Folin-Ciocalteu reagent were added to $2325 \mu \mathrm{L}$ of distilled water. Then, $100 \mu \mathrm{L}$ of a $\mathrm{Na}_{2} \mathrm{CO}_{3}$ solution ( $20 \%$ prepared in $\mathrm{NaOH} 0.1 \mathrm{M}$ ) was added. After $90 \mathrm{~min}$ of reaction at room temperature $\left(25^{\circ} \mathrm{C}\right)$ the absorbance was measured at $750 \mathrm{~nm}$, and results were expressed as $\mathrm{mg}$ of gallic acid per $\mathrm{g}$ of dry melanoidin (Hasperué et al., 2015). The antioxidant activity of MRP was determined by DPPH and FRAP methods as previously described.

\section{Differential scanning calorimetry (DSC) analysis on melanoidins}

A Q100 differential scanning calorimeter (TA Instruments, USA) was used to study the thermal transitions of BSG melanoidins. Freeze-dried samples $(1.5 \mathrm{mg})$ were heated from $20{ }^{\circ} \mathrm{C}$ to $300{ }^{\circ} \mathrm{C}\left(10^{\circ} \mathrm{C} / \mathrm{min}\right)$ in sealed pans (Manzocco et al., 1999). The enthalpy and peak temperature were obtained from the thermograms. Assays were performed at least in duplicate.

\section{X-ray diffraction (XRD)}

X-ray diffraction analysis was performed using a Philips diffractometer-APD PW 1710. Samples were irradiated with $\mathrm{Cu}$ Ka radiation $(1.542 \AA)$ using $30 \mathrm{~mA}$ and $40 \mathrm{kV}$. The diffraction patterns were obtained in the range of $3-50^{\circ}(2 \theta)$ at a scan speed of $0.04 \mathrm{~s}^{-1}$ (Kang, 2016)

\section{Fourier transform infrared spectroscopy (FTIR)}

The infrared spectra of the samples were recorded between 4000 and $650 \mathrm{~cm}^{-1}$ at a resolution of $4 \mathrm{~cm}^{-1}$ using a Nicolet iS10 spectrometer (Thermo Scientific, USA) mounted with an attenuated total reflectance (ATR) accessory. Sixty-four scans were co-added for 
each spectrum to improve the signal-to-noise ratio. The powder was directly placed on a single reflection diamond ATR accesory and pressed to have a good contact between the crystal and sample. Spectra processing was performed using the software EZ Omnic (Thermo Electron Corporation, USA).

\section{Statistical analysis}

Results were statistically evaluated by analysis of variance (ANOVA) at a 0.05 significance level. The least significant differences (LSD) were determined by comparing the means at a 95\% confidence level using the Fisher's test (InfoStat, 2012;UNC, Argentina).

\section{Results and Discussion}

\section{Antioxidant activity of BSG}

In the present work, the release of bioaccessible antioxidant compounds was determined through a standardized static in vitro digestion method. Besides, the antioxidant capacity of the non-bioaccessible fraction was also considered as it may protect epithelial cells in the colon (Patrignani et al., 2019). Because of the complexity of oxidative reactions, a combination of antioxidant tests was used in order to obtain accurate results. FRAP and DPPH showed that the antioxidant capacity significantly increased with the roasting degree of the BSG $(P \leq 0.05)$. According to the results, the highest total antioxidant activity was found in Chocolate BSG $(0.2 \mu \mathrm{mol} / \mathrm{mg}$ and $0.03 \mu \mathrm{mol} / \mathrm{mg}$ according to FRAP and DPPH analyses respectively) (Fig. 1). Other authors had previously determined the antioxidant capacity of BSG, but their results were significantly lower Connolly et al. (2013) indicated that the highest content of antioxidants in BSG determined by FRAP was $0.02 \mu \mathrm{mol} / \mathrm{mg}$, while Ivanova et al. (2017) reported $0.006 \mu \mathrm{mol} / \mathrm{mg}$ and 0.005 $\mu \mathrm{mol} / \mathrm{mg}$ according to FRAP and DPPH assays. Although ABTS assay did not indicate any significant difference among the samples $(P>0.05)$, the antioxidant capacity determined with this method was also significantly higher than previous studies. Socaci et al. (2018) found that the antioxidant capacity of BSG by ABTS was $6.10^{-6} \mu \mathrm{mol} / \mathrm{mg}$; in 
contrast, our results showed that the antioxidant content of BSG was $0.15 \mu \mathrm{mol} / \mathrm{mg}$ when an in vitro digestion process was used. The low values of antioxidant capacity found in previous works could be due to the chemical extraction used to release the bioactive compounds from the food matrix. Delgado-Andrade et al. (2010) indicated that the use of an in vitro digestion procedure is a critical step that allows the release of a large amount of antioxidant compounds and results can be considered more nutritionally relevant than the values determined in organic extracts.

Moreover, even though the BSG has a high proportion of fibre, most of its antioxidants could be successfully released from the food matrix by the digestive enzymes. This indicates that most antioxidants from BSG are bioaccessible and potentially bioavailable depending on their absorption through the intestinal wall (Patrignani et al., 2019). It could be concluded that, although the use of different solvents to extract antioxidants in cereal-based foods is a common practice, it may be incomplete or inadequate for BSG (Delgado-Andrade et al., 2010). According to our results, BSG could be considered a more important source of bioavailable antioxidants than what it was previously reported.

\section{Composition and antioxidant capacity of isolated BSG melanoidins}

Although melanoidins are one of the most important antioxidant compounds in BSG, their structure is largely unknown (Piggott et al., 2014). The complexity of MR, in addition to the difficulty in purifying and identifying the melanoidins, makes their analysis challenging (Pastoriza and Rufián-Henares, 2014).

In the present work, the proportion of melanoidins in the BSG ranged from $6 \%$ $10 \%$ with no significant difference among the samples $(P>0.05)$ (data not shown). These values compare well with those reported by Pastoriza and Rufián-Henares (2014) who indicated that the melanoidin content in Pilsen and Black beer was $8 \%$ and $15 \%$ respectively. Moreover, according to the results displayed in Table 1, BSG isolated melanoidins had a low protein content and a high proportion of carbohydrates (73\%-85\%) (Table 1). This result is also in good agreement with Pastoriza and Rufián-Henares (2014), who found that the protein proportion in melanoidins isolated from beer was $72 \pm$ 
$2 \%$. Therefore, it could be considered that melanoidins extracted from BSG have similar characteristics to melanoidins isolated from beer.

On the other hand, as detailed in Table 1, the protein content of the melanoidins was associated with the roasting degree of the BSG $(P \leq 0.05)$. The highest amount of protein was found in Pilsen BSG melanoidin $(4.81 \%)$, while the other samples showed a significantly lower proportion of this component $(0.6 \%-1 \%)(P \leq 0.05)$. Besides, there was a low presence of phenolic compounds within the structure of melanoidins. This was previously reported by Piggott et al. (2014) in MRP derived from BSG, who supported the idea that these MRP have a carbohydrate-phenol based structure. Moreover, according to De La Cruz et al. (2019), during the roasting process phenolic compounds could bind to the initial melanoidin skeleton composed of carbohydrates and proteins. Phenolic compounds, are well known because of their strong antioxidant activity, and it is probable that they could act together with the melanoidins in the gastrointestinal tract (SauraCalixto, 2011). It is therefore possible that the biological functions of MRP might be associated, with the presence of phenolic compounds in their structure.

Finally, the antioxidant capacity of the isolated melanoidins was determined by DPPH and FRAP (Table 1). Consistent with results obtained after in vitro digestion of the BSG (see previous section), the lowest antioxidant capacity was found in melanoidins extracted from Pilsen BSG, while roasted samples presented a higher antioxidant activity $(P \leq 0.05)$.

\section{UV-Vis spectrum of melanoidins}

The absorption spectra of the different melanoidins were recorded in the four samples analysed. Absorbance at $294 \mathrm{~nm}$ is associated with the presence of early and low molecular weight MRP, while the development of high molecular weight MRP can be followed by an increase in the absorbance at $420 \mathrm{~nm}$. Therefore, these values can be used as arbitrary measurements of melanoidin presence (Patrignani et al., 2019). As illustrated in Fig. 2, the Abs420 and Abs294 of melanoidins increased with the roasting intensity of the BSG. Therefore, it could be established that the browning level of MRP in the samples was in the following order: Pilsen $<$ Caramel $60 \approx$ Caramel $120<$ Chocolate. 
The absorbance parameters of the isolated melanoidins in pale and black beer $\left(\mathrm{K}_{420}=0.33 \mathrm{~L} / \mathrm{g} . \mathrm{cm}\right.$ and $\mathrm{K}_{420}=0.52 \mathrm{~L} / \mathrm{g} . \mathrm{cm}$ respectively) determined by Pastoriza and Rufián-Henares (2014) were consistent with the ones found in the present work in Pilsen $\left(\mathrm{K}_{420}=0.33 \mathrm{~L} / \mathrm{g} . \mathrm{cm}\right)$ and Chocolate $\left(\mathrm{K}_{420}=0.66 \mathrm{~L} / \mathrm{g} . \mathrm{cm}\right)$ BSG melanoidins. On the other hand, the high absorbance found in far UV confirms the presence of peptide bonds in melanoidin structure (Patrignani et al., 2019).

\section{DSC analysis of melanoidins}

DSC analysis is a widely accepted methodology to study the thermal behaviour of food. However, few researchers have attempted to detect the changes in enthalpy involved in the MR by DSC and published data are scarce (Manzocco et al., 1999). In the present work, an endothermal peak was observed in the thermograms of melanoidins extracted from BSG. The thermograms together with the enthalpy values $(\Delta H)$ are shown in Fig. 3. According to the results, the $\Delta \mathrm{H}$ of the peak decreased with the roasting degree of the samples, suggesting that it may be related to the presence of proteinic structures that are lost because of the thermal treatment (Biliaderis, 1983). Moreover, the peak temperature also seemed to increase with the thermal treatment. These results are consistent with Manzocco et al. (1999) who studied the thermal changes of glucose-glycine model systems. According to their results the prolonged heating of the solution caused the progressive browning of the samples which was associated with a decrease in $\Delta \mathrm{H}$. Besides, their results showed that the temperature of the peak shifted from $120^{\circ} \mathrm{C}$ to $150^{\circ} \mathrm{C}$. However, these analyses were performed in model systems, and currently there are no references available about the thermal behaviour of real systems such as melanoidins extracted from BSG.

Therefore, it could be concluded that DSC analysis could be a useful methodology to evaluate the development of MR. Nonetheless, future studies should be carried out on real food systems in order to expand our knowledge about the thermal behaviour of MRP.

\section{X-ray diffraction patterns of melanoidins}


The X-ray diffraction patterns were performed to examine the crystallinity of BSG melanoidins. According to the results displayed in Fig. 4, broad diffraction peaks were found and important differences among roasted and non-roasted samples were observed. Pilsen melanoidins presented a main peak at $12^{\circ}(2 \theta)$ while other samples showed a peak centred at $20^{\circ}(2 \theta)$. These differences are due to the different conformations in the chemical structure related to the evolution of MR (Khadidja et al., 2017). Also, it can be observed that as the roasting degree increased, the crystallinity was reduced (Fig. 4). In good agreement, other authors have reported that the development of MR reduces the crystallinity of the reactants (Lin et al., 2019).

Although Caramel 60 and 120 presented a lower development of MR than Chocolate melanoidins (see previous section), their diffraction patterns were extremely similar. Therefore, it could be speculated that during the development of MR, the crystallinity is reduced and the structure sets into a new and different conformation with a peak centred at $20^{\circ}(2 \theta)$. This final conformation seems to be stable and it is not modified with the increasing thermal treatment.

\section{FT-IR analysis}

FTIR spectroscopy was used for the analysis of the derivatives formed during the nonenzymatic browning reaction (Fig. 5). The broad, intense stretching signal at $3308 \mathrm{~cm}^{-1}$ represents hydroxyl in water and amine groups (Borel et al., 2018; Silbir and Goksungur, 2019). The signal around $2900 \mathrm{~cm}^{-1}$ can be related to the asymmetric stretch $(\mathrm{nC}-\mathrm{H})$ of $\mathrm{CH}_{2}$ groups and the corresponding symmetric stretch can be observed at $2855 \mathrm{~cm}^{-1}$. This last signal at $2855 \mathrm{~cm}^{-1}$ is progressively lost from Pilsen to Chocolate, which indicates a structure modification when MR takes place.

The region between 1650 and $1540 \mathrm{~cm}^{-1}$ is related to amide I and amide II structures, including $\mathrm{C}=\mathrm{O}$ and $\mathrm{C}-\mathrm{N}$ stretching and $\mathrm{N}-\mathrm{H}$ deformation. While the adsorption band around $1300-1200 \mathrm{~cm}^{-1}$ can be attributed to amide III structures, including C-N stretching and $\mathrm{N}-\mathrm{H}$ deformation. Changes of amide I and amide II bands in Fig. 5 show that hydroxyl and amino groups were consumed during the heating process. In particular, the band at $1543 \mathrm{~cm}^{-1}$ showed a significant decrease in intensity when the roasting degree increased (Fig. 5 (a) to (d)). These results are in accordance with previous 
studies performed by Khadidja et al. (2017) in aqueous model systems containing gelatin and sodium alginate. Their results suggested that during the cross-linking of the material, proteinic structures may be lost. This was also observed in our study during the development of BSG melanoidins, and it is in good line with results shown in Table 1 and Fig. 3, which indicated that the protein structure of melanoidins was significantly reduced with the roasting degree.

The region between 1180 and $953 \mathrm{~cm}-1$ is related to saccharide bonds vibrational modes, such as C-C and C-O stretching, and C-H bending (Kim and Lee, 2009; Borel et al., 2018). The absorption at $1148 \mathrm{~cm}^{-1}$ indicated a dominance of $\alpha$-glycosidic linkage (Mutaillifu et al., 2020). The increase of this band with the roasting degree may be associated with formation of a melanoidin skeleton with carbohydrate side chains. This is also supported with results displayed in Table 1, which show that the proportion of carbohydrates was higher in the samples with an important roasting degree.

On the other hand, the number of compounds associated with non-enzymatic browning, such as the Amadori compounds $(\mathrm{C}=\mathrm{O})$, Schiff base $(\mathrm{C}=\mathrm{N})$, and pyrazines $(\mathrm{C}-$ N) may increase during MR (Farhat et al., 1998). As detailed in Fig. 5, the peak at 1077 $\mathrm{cm}^{-1}$ showed an increase in intensity in good line with the malt roasting degree, which suggests the presence of furanose rings in the melanoidin structure. These basic structural units in melanoidins have been reported in previous studies (Bruhns et al., 2019).

\section{Conclusions}

BSG is an important source of bioaccessible melanoidins with high antioxidant activity. The current results indicate that during the roasting process melanoidin structure is modified, proteinic structures are significantly reduced and phenolic compounds bind to the increasing carbohydrate skeleton. The crystallinity is also reduced and the structure sets into a new and different conformation with a peak centred at $20^{\circ}(2 \theta)$ that is stable with the increasing roasting process. While MR continues, absorbance of melanoidins increases together with the antioxidant activity. FTIR analysis showed a dominance of $\alpha$ glyosidic linkage and the presence of furanose rings in BSG melanoidin structure. 
Although the potential uses of melanoidins are still undervalued, the analysis of their structure is the first step to open new fields of application and give a better understanding of their physiological effects.

\section{Acknowledgements}

The experiments were financially supported by CONICET, UNLP and MINCYT.

\section{Conflict of Interest}

The authors declare having no conflict of interest.

\section{Data Availability Statement}

Data that support our findings are available upon request to the authors.

\section{Ethical Guidelines}

Ethical approval was not required for this research

\section{References}

Biliaderis, C.G. (1983). Differential scanning calorimetry in food research-A review. Food Chemistry, 10, 239-265.

Borel, L.D.M.S., Lira, T.S., Ribeiro, J.A., Ataíde, C.H. \& Barrozo, M.A.S. (2018). Pyrolysis of brewer's spent grain: Kinetic study and products identification. Industrial Crops and Products, 121, 388-395.

Bruhns, P., Kanzler, C., Degenhardt, A.G., Koch, T.J. \& Kroh, L.W. (2019). Basic Structure of Melanoidins Formed in the Maillard Reaction of 3-Deoxyglucosone and Y-Aminobutyric Acid. Journal of Agricultural and Food Chemistry, 67, 5197-5203.*

Carvalho, D. O., Correia, E., Lopes, L. \& Guido, L. F. (2014). Further insights into the role of melanoidins on the antioxidant potential of barley malt. Food Chemistry, 160, 127133.

Connolly, A., Piggott, C.O. \& Fitzgerald, R.J. (2013). Characterisation of protein-rich isolates and antioxidative phenolic extracts from pale and black brewers' spent grain. International Journal of Food Science and Technology, 48, 1670-1681.* 
De La Cruz, S.T., Iriondo-DeHond, A., Herrera, T., Lopez-Tofiño, Y., Galvez-Robleño, C., Prodanov, M., Velazquez-Escobar, F., Abalo, R. \& Castillo, M.D. Del. (2019). An assessment of the bioactivity of coffee silverskin melanoidins. Foods, 8, 1-20.

Delgado-Andrade, C., Conde-Aguilera, J.A., Haro, A., Pastoriza de la Cueva, S. \& Rufián-Henares, J.Á. (2010). A combined procedure to evaluate the global antioxidant response of bread. Journal of Cereal Science, 52, 239-246.

Farhat, I.A., Orset, S., Moreau, P. \& Blanshard, J.M.V. (1998). FTIR study of hydration phenomena in protein-sugar systems. Journal of Colloid and Interface Science, 207, 200-208.

Hasperué, J.H., Lemoine, L., Vicente, A.R., Chaves, A.R. \& Martínez, G.A. (2015). Postharvest senescence of florets from primary and secondary broccoli inflorescences. Postharvest Biology and Technology, 104, 42-47.

Ivanova, K., Denkova, R., Kostov, G., Petrova, T., Bakalov, I., Ruscova, M. \& Penov, N. (2017). Extrusion of brewers' spent grains and application in the production of functional food. Characteristics of spent grains and optimization of extrusion. Journal of the Institute of Brewing, 123, 544-552.

Kang, O.J. (2016). Evaluation of melanoidins formed from black garlic after different thermal processing steps. Preventive Nutrition and Food Science, 21, 398-405.*

Khadidja, L., Asma, C., Mahmoud, B. \& Meriem, E. (2017). Alginate/gelatin crosslinked system through Maillard reaction: preparation, characterization and biological properties. Polymer Bulletin, 74, 4899-4919.

Kim, J.S. \& Lee, Y.S. (2009). FT-IR and X-RAY diffraction characterization of melanoidins formed from glucose and fructose with amino acid enantiomers in the Maillard reaction. Food Science and Biotechnology, 18, 546-551.*

Lin, Q., Li, M., Xiong, L., Qiu, L., Bian, X., Sun, C. \& Sun, Q. (2019). Characterization and antioxidant activity of short linear glucan-lysine nanoparticles prepared by Maillard reaction. Food Hydrocolloids, 92, 86-93.

Lynch, K. M., Steffen, E. J. \& Arendt, E. K. (2016). Brewers' spent grain: a review with an emphasis on food and health. Journal of the Institute of Brewing, 122, 553-568.

Manzocco, L., Nicoli, M.C. \& Maltini, E. (1999). DSC analysis of maillard browning and procedural effects. Journal of Food Processing and Preservation, 23, 317-328.

Mohsin, G.F., Schmitt, F.J., Kanzle, C., Epping, J.D., Buhrke, D. \& Hornemann, A. 
(2020). Melanoidin formed from fructosylalanine contains more alanine than melanoidin formed from D-glucose with L-alanine. Food Chemistry, 305, 125459.

Mutaillifu, P., Bobakulov, K., Abuduwaili, A., Huojiaaihemaiti, H., Nuerxiati, R., Aisa, H.A. \& Yili, A. (2020). Structural characterization and antioxidant activities of a water soluble polysaccharide isolated from Glycyrrhiza glabra. International Journal of Biological Macromolecules.

Olajire, A. A. (2020). The brewing industry and environmental challenges. Journal of Cleaner Production, 256, 1-22.

Palmer, J.J. (2006). How to Brew: Everything you need to know to brew beer right the first time. Boulder, Colorado: Brewers Publications.

Pastoriza, S. \& Rufián-Henares, J.A. (2014). Contribution of melanoidins to the antioxidant capacity of the Spanish diet. Food Chemistry, 164, 438-445.

Patrignani, M., Rinaldi, G.J., Rufián-Henares, J.Á. \& Lupano, C.E. (2019). Antioxidant capacity of Maillard reaction products in the digestive tract: An in vitro and in vivo study. Food Chemistry, 276, 443-450.

Piermaria, J., Diosma, G., Aquino, C., Garrote, G. \& Abraham, A. (2015). Edible kefiran films as vehicle for probiotic microorganisms. Innovative Food Science \& Emerging Technologies, 32, 193-199.

Piggott, C.O., Connolly, A. \& FitzGerald, R.J. (2014). Application of ultrafiltration in the study of phenolic isolates and melanoidins from pale and black brewers' spent grain. International Journal of Food Science and Technology, 49, 2252-2259.*

Saura-Calixto, F. (2011). Dietary fiber as a carrier of dietary antioxidants: An essential physiological function. Journal of Agricultural and Food Chemistry, 59, 43-49.

Silbir, S. \& Goksungur, Y. (2019). Natural red pigment production by monascus purpureus in submerged fermentation systems using a food industry waste: Brewer's spent grain. Foods, 8.

Socaci, S.A., Fărcaş, A.C., Diaconeasa, Z.M., Vodnar, D.C., Rusu, B. \& Tofană, M. (2018). Influence of the extraction solvent on phenolic content, antioxidant, antimicrobial and antimutagenic activities of brewers' spent grain. Journal of Cereal Science, 80, 180-187.

Wang, H.Y., Qian, H. \& Yao, W.R. (2011). Melanoidins produced by the Maillard reaction: Structure and biological activity. Food Chemistry, 128, 573-584. 
Yang, S., Fan, W., \& Xu, Y. (2019). Melanoidins from Chinese Distilled Spent Grain: Content, preliminary structure, antioxidant, and ACE-Inhibitory activities invitro. Foods, 8, 1-15.*

\section{Annoted references}

The references with asterisks are key because, among those cited and listed, these studies deal with important advances in the characterization of melanoidins.

\section{Supporting Information}

Additional Supporting Information may be found in the online version of this article 
Table 1. Protein content, carbohydrate content, antioxidant capacity and total phenolic content of melanoidins extracted from different BSG (Pilsen, Caramel 60, Caramel 120, and Chocolate)

\begin{tabular}{|c|c|c|c|c|c|}
\hline & $\begin{array}{c}\text { Protein content } \\
\qquad(\%)\end{array}$ & $\begin{array}{l}\text { Carbohydrate } \\
\text { content (\%) }\end{array}$ & $\begin{array}{l}\text { TPC } \\
(\%)\end{array}$ & $\begin{array}{c}\text { FRAP } \\
(\mu \mathrm{g} \text { Trolox/mg) }\end{array}$ & $\begin{array}{c}\text { DPPH } \\
(\mu \mathrm{g} \text { Trolox/mg) }\end{array}$ \\
\hline $\begin{array}{l}\text { Melanoidin of } \\
\text { Pilsen BSG }\end{array}$ & $4.81 \pm 0.69^{b}$ & $72.8 \pm 3.6^{a}$ & $8.84 \pm 0.78^{a}$ & $19.28 \pm 0.04^{a}$ & $1.43 \pm 0.62^{a}$ \\
\hline $\begin{array}{c}\text { Melanoidin of } \\
\text { Caramel } 60 \\
\text { BSG }\end{array}$ & $1.00 \pm 0.04^{a}$ & $76.16 \pm 3.32^{\mathrm{ab}}$ & $14.88 \pm 2.50^{\mathrm{ab}}$ & $37.4 \pm 2.00^{b}$ & $18.00 \pm 3.00^{c}$ \\
\hline $\begin{array}{c}\text { Melanoidin of } \\
\text { Caramel } 120 \\
\text { BSG }\end{array}$ & $0.64 \pm 0.19^{a}$ & $86.62 \pm 11.08^{b}$ & $18.11 \pm 3.70^{b}$ & $40.40 \pm 1.65^{b}$ & $9.15 \pm 0.44^{b}$ \\
\hline $\begin{array}{l}\text { Melanoidin of } \\
\text { Chocolate BSG }\end{array}$ & $1.00 \pm 0.25^{a}$ & $84.8 \pm 3.14^{b}$ & $18.38 \pm 0.74^{b}$ & $51.34 \pm 1.13^{c}$ & $8.80 \pm 2.60^{b}$ \\
\hline
\end{tabular}

Results are expressed as mean \pm standard deviation. Values in the same column followed by different superscript letters are significantly different $(P \leq 0.05)$. 


\section{Legends to Figures}

\section{Fig.1}

Bioaccessible (soluble fraction), insoluble (solid residue) and total antioxidant activity after the in vitro digestion process of BSG with different roasting degree. Determinations were performed with $\operatorname{FRAP}(a), \operatorname{DPPH}(b)$ or $A B T S(c)$ assays. Different letters indicate significant differences between the different antioxidant fractions $(P \leq 0.05)$. Results represent mean \pm standard deviation.

Fig. 2

Absorption spectra of BSG melanoidins $(0.6 \mathrm{mg} / \mathrm{ml})$ (Pilsen, Caramel 60, Caramel 120 and Chocolate). Results represent mean \pm standard deviation.

\section{Fig. 3}

DSC curve of melanoidins isolated from Pilsen, Caramel 60, Caramel 120 and chocolate BSG.

Fig. 4

X-ray diffractograms of melanoidins isolated from Pilsen, Caramel 60, Caramel 120 and chocolate BSG.

\section{Fig. 5}

FTIR spectra of melanoidins isolated from Pilsen (a), Caramel 60 (b), Caramel 120 (c) and chocolate BSG (d) in the $3800-600 \mathrm{~cm}^{-1}$ region. 
Fig. 1

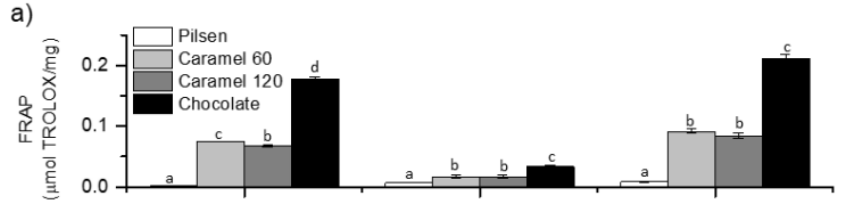

b)
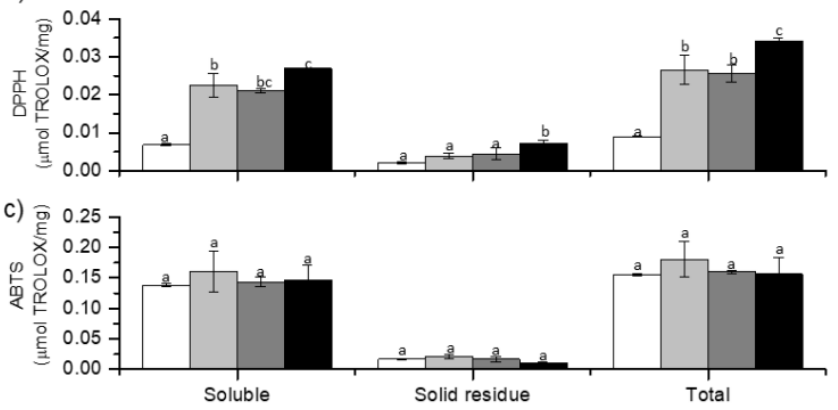

ijfs_14653_f1.tif 
Fig. 2

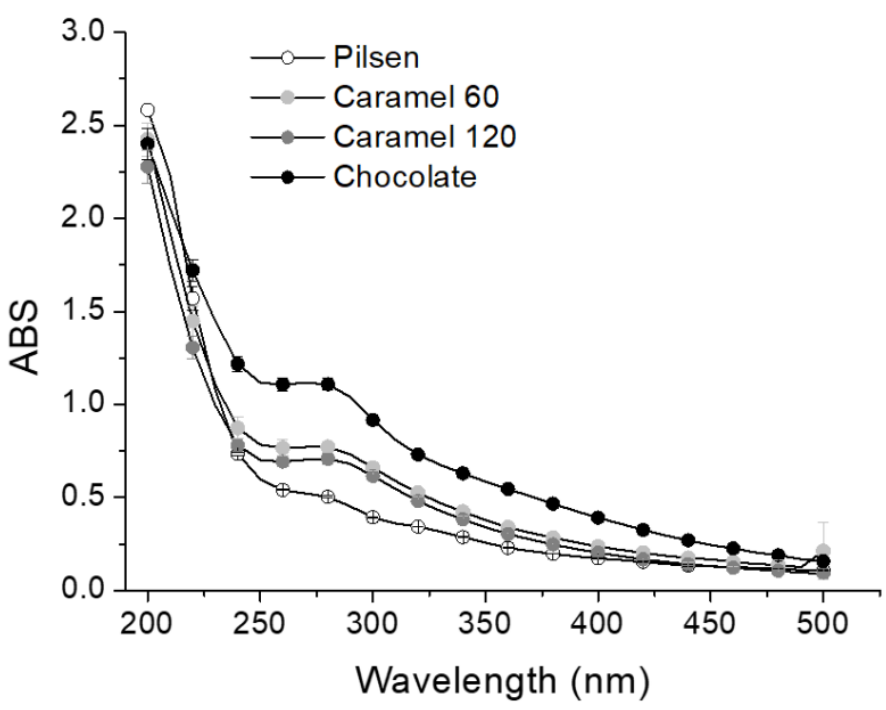

ijfs_14653_f2.tif 


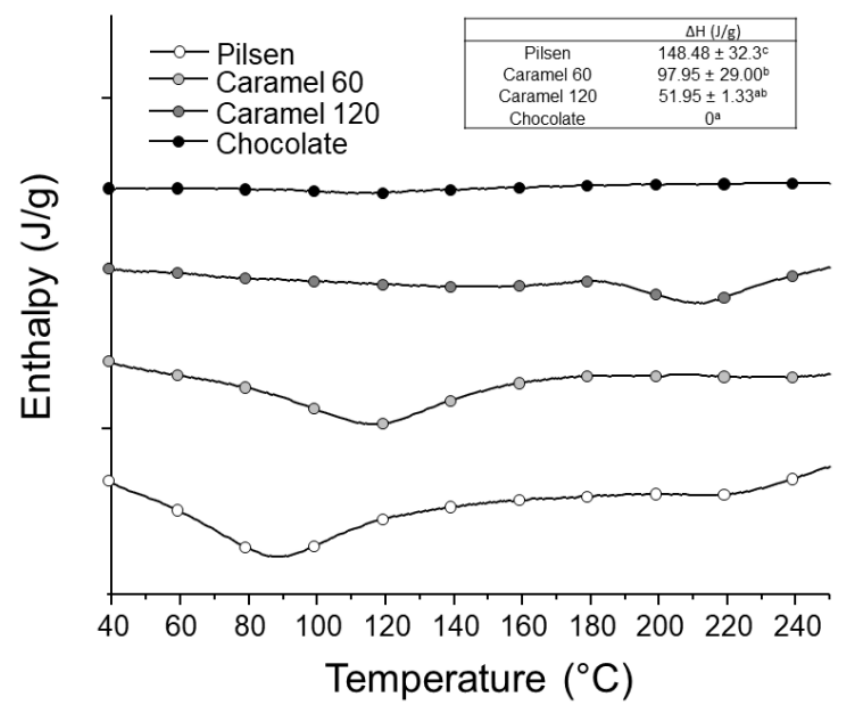

ijfs_14653_f3.tif 
Fig. 4

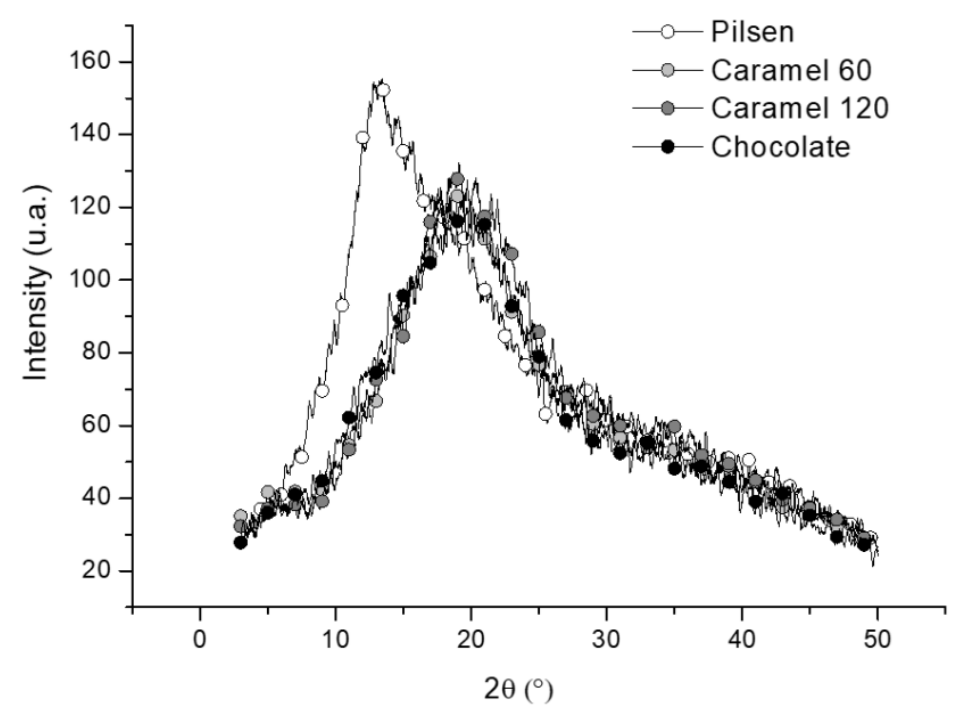

ijfs_14653_f4.tif

This article is protected by copyright. All rights reserved 


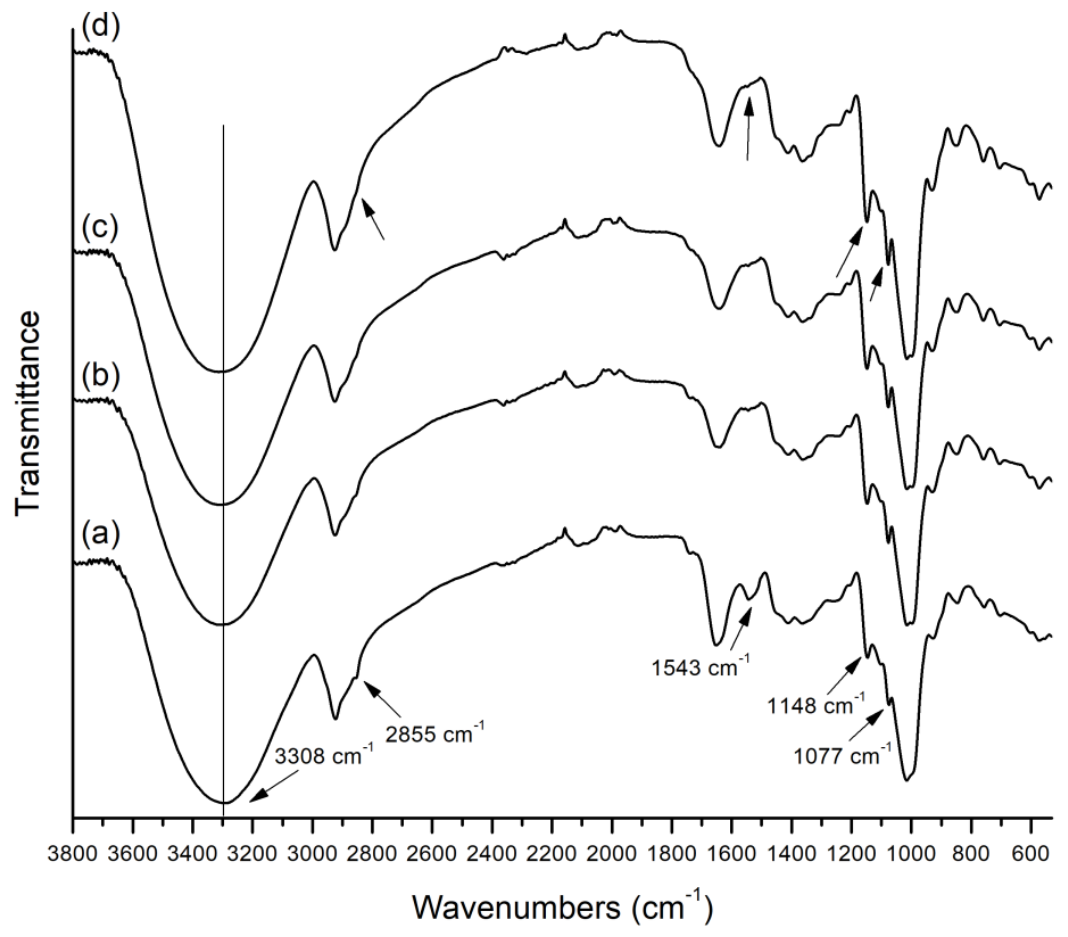

ijfs_14653_f5.tif

This article is protected by copyright. All rights reserved 